\title{
Salinity Effects on Survival and Reproduction of Hydrozoan Eleutheria dichotoma
}

\author{
Aleksandra Dańko $^{1} \cdot$ Ralf Schaible ${ }^{1}$ - Maciej J. Dańko ${ }^{1}$ (DD
}

Received: 6 July 2018 / Revised: 6 December 2019 / Accepted: 10 December 2019 / Published online: 23 December 2019

(C) The Author(s) 2019

\begin{abstract}
Salinity conditions experienced by organisms in coastal regions may shape their life histories. Here, salinity's impact on reproduction and survival of the hydrozoan Eleutheria dichotoma was investigated using laboratory-cultured individuals originating from Banyuls-sur-Mer (southern France) collected several decades ago. During the experiment (October 2014-July 2015), hydroid colonies and medusae were exposed to three salinities $(25,35,45)$. Asexually budded medusae were collected from colonies and reared for three generations obtained by asexual budding of medusae. Salinities experienced by hydroid colonies had only minor effects on initial size, time to maturity, medusa budding, sexual production of planulae by medusae, and survival. In contrast, salinities experienced by medusae influenced their life histories. Compared with medium salinity (35), lowsalinity medusae (25) had an earlier onset and higher rates of asexual budding, a later onset and slower rates of sexual reproduction, and higher mortality, which could result from allocation tradeoffs. The increased production of planulae by medusae in low salinity indicated that they were transitioning to a benthic polyp life form more resistant to environmental stress. High salinity (45) delayed asexual maturity, prevented sexual maturity in medusae, and led to lower survival and asexual reproduction rates. Budding rates decreased across the generations; however, planula production rates decreased in medium salinity but increased in low salinity. This might be explained by the accumulation of damage with each generation, and/or by internal rhythms. The flexible responses of this tractable model organism, Eleutheria dichotoma, to salinity change may be useful in future studies on changing estuarine conditions.
\end{abstract}

Keywords Asexual vs. sexual reproduction $\cdot$ Budding medusae $\cdot$ Complex life cycle $\cdot$ Internal rhythms $\cdot$ Resource allocation

\section{Introduction}

Temperature and salinity are key factors affecting the physiological and ecological responses of organisms inhabiting estuaries and brackish waters (e.g., Kinne 1970; Remane and Schlieper 1972). While water temperature varies seasonally,

Aleksandra Dańko and Maciej J. Dańko contributed equally to this work.

Communicated by Paul A. Montagna

Electronic supplementary material The online version of this article (https://doi.org/10.1007/s12237-019-00675-2) contains supplementary material, which is available to authorized users.

Maciej J. Dańko

danko@demogr.mpg.de

Aleksandra Dańko

adanko481@gmail.com

1 Laboratory of Evolutionary Biodemography, Max Planck Institute for Demographic Research, 18057 Rostock, Germany salinity is relatively stable in most of the open sea. In contrast, the salinity of coastal waters changes due to factors like extensive rainfall, river inputs, and low tides in conjunction with high environmental temperatures (e.g., Poulos et al. 1997). The most challenging systems with potentially high levels of variation in salinity include estuaries, lagoons, bays, beaches, and tidepools. Environments with variable salinity are often less diverse, because many taxa, including cnidarians, have few species that can tolerate these conditions (Dumont 1994). On the other hand, species that can adapt to a wide range of salinities (i.e., euryhaline species) may exhibit high invasive potential (e.g., Purcell 2005; Freire et al. 2014; Folino-Rorem and Renken 2018).

Changes in salinity can cause osmotic stress, which is associated with cell shrinkage or lysis. Cell volume regulation is a mechanism for coping with osmotic stress on the cellular level (Hoffmann and Pedersen 2011). The physiological regulation of cell volume involves osmoregulation (ionic regulation of intra- and extracellular fluids through ion channels, ion exchange proteins, or primary ion pumps) and osmotic 
adaptation (through intracellular concentration of osmotically active substances like free amino acids (e.g., Schubert et al. 2017). Osmoregulation is an energetically costly process used by many invertebrates, and by all vertebrates, to maintain a balance in ionic concentration levels inside and outside the cells that is physiologically appropriate (Sokolova et al. 2012). However, many marine invertebrates do not perform osmotic regulation of their extracellular fluid, and instead rely solely on the intracellular regulation of cell volume. These so-called osmoconformers are normally restricted to marine waters and are adapted to narrow ranges of salinity (Rivera-Ingraham and Lignot 2017). Generally, osmoconformers should have lowerenergy requirements than osmoregulators when exposed to low salinity, as cell volume regulation in these conditions is achieved by lowering the internal ionic concentration (e.g., Bradley 2009). Nonetheless, exposure to both hypo-osmotic and hyper-osmotic shocks can be associated with increased respiratory rates, and thus with free radical production and cellular damage (reviewed in Rivera-Ingraham and Lignot 2017). Even using the opposite strategy of metabolic arrest, which has been observed in the hypo-osmotic conditions of some osmoconformers, can be associated with production of free radicals (e.g., Rivera-Ingraham et al. 2016). At elevated salinities, energy requirements may be high, probably due to increased respiratory rates, aerobic metabolism, and production of osmotically active substances such as methylamines, free amino acids and derivatives, and different antioxidants (Rivera-Ingraham and Lignot 2017; Schubert et al. 2017).

Oxidative stress can directly accelerate senescence (Finkel and Holbrook 2000). Senescence can also be indirectly accelerated by shifting resource allocation from tissue maintenance and repairs to the metabolic costs of osmoregulation (Kozłowski 1992; Cichoń 1997). Indeed, different forms of osmoregulation can compromise many aspects of an organism's life-sustaining processes, including immune defense (e.g., Birrer et al. 2012; Nadirah et al. 2018), growth (e.g., Bøhle 1972; Pechenik et al. 2000; Sampaio and Bianchini 2002), and reproduction (e.g., Rippingale and Kelly 1995; Purcell et al. 1999; Pechenik et al. 2000; Yin and Zhao 2008). Some of these effects may be related to resource allocation, and while others may result from physiological constraints. For example, growth and reproduction in cnidarians may be associated with differences in food ingestion driven by salinity change (e.g., Folino-Rorem and Renken 2018).

The hydrozoan Eleutheria dichotoma (Cnidaria: Hydrozoa: Anthoathecata: Cladonematidae) is a promising model organism for studying how life histories adapt to salinity (Hadrys et al. 1990). This species occurs in many locations (Fraser et al. 2006; Schubert et al. 2017). It has been found along the Atlantic coast of Europe, including Norway (average surface salinity 35; Belkin et al. 1998), the Mediterranean (surface salinity varies between 36 (west) and 39.5 (east); Soukissian et al. 2017), and the Black Sea (surface salinity varies between 14 and 19, with an average of 18 ; Leonov 2005), but probably does not occur in the Baltic Sea (average surface salinity 10; Madsen and Höjerslev 2009). Eleutheria dichotoma has also been found, as a nonindigenous species, along the east coast of Australia (Fraser et al. 2006). The species inhabits coastal intertidal areas and shallow depths and is most frequently found in tidepools. Such habitats can be exposed to considerable variation in salinity due to flushing rates, seasonal changes (freezing, evaporation, rainfall), and the distance of the tidepools from the shore (Metaxas and Scheibling 1993).

Eleutheria dichotoma occurs in three main life forms: a hydroid colony, a crawling medusa, and a planula. The hydroid colony produces hydranths and medusa buds asexually, which are released at an advanced stage of development; i.e., when the tentacles are well-developed (Hauenschild 1956) (Figs. 1 and 2). The crawling medusae have the extraordinary feature of being able to reproduce both sexually and asexually (Hauenschild 1956; Schierwater and Hadrys 1998). Asexual reproduction in medusae occurs via the formation of medusa buds on their umbrella rim, which are later released (Hauenschild 1956; Schuchert 2009).

While asexual reproduction seems to be more efficient in the short run, it may lead to the accumulation of deleterious mutations and molecular damage in a process known as Muller's ratchet (Felsenstein 1974); and, thus, to a gradual deterioration of the genetic line (Loewe and Cutter 2008). The most obvious way to avoid such deterioration is to allow for genetic recombination through sexual reproduction and subsequent selection (Maynard Smith et al. 1978). Theoretically, this mechanism cannot be effective in E. dichotoma, which is a hermaphrodite that self-fertilizes. Reproductive organs of E. dichotoma are found inside the brood pouch, and fertilization occurs internally (Hauenschild 1956). This strategy may raise questions about how this species maintains genetic diversity. However, studies on the genetic background of E. dichotoma in the wild have shown that there is a high degree of diversity among and within populations. This diversity may be attributable to the segregation of gene complexes and subsequent selection, as well as high mutation rates (Ender 1997).

Planulae initially develop as embryos in a brood pouch on the aboral side of medusae, and are released by bursting the umbrella (Schierwater and Hadrys 1998). Planulae then settle on a solid substrate and can initiate a new hydroid colony. Although hydroid colonies are cryptic and rarely found in the wild (Mills and Hirano 2007; Schuchert 2009), medusae are frequently observed from early spring to late autumn (Schierwater and Hauenschild 1990).

The ability to reproduce both sexually and asexually appears to help medusae make efficient use of the available resources. While asexual budding can quickly increase the number of crawling medusae, the planula larvae can disperse, select a site, and start a new hydroid colony generation (Bell 1982; but see 


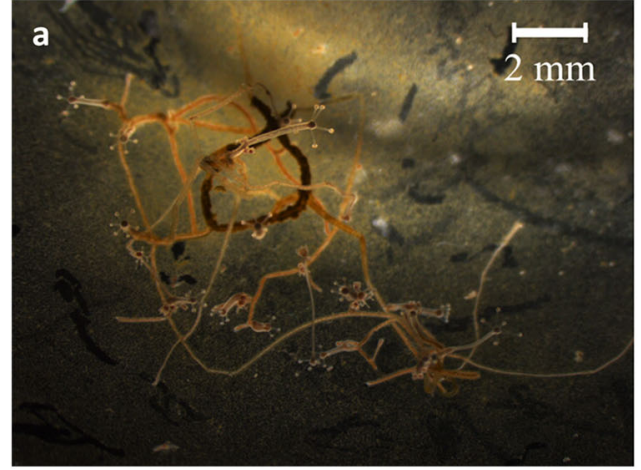

Fig. 1 The hydroid colony of Eleutheria dichotoma (a) grows by producing stolon (hydrorhiza) and its branches (hydrocladia) bearing one or more polyps (hydranths). The hydranths reproduce asexually by

also Ma and Purcell 2005; Dańko et al. 2018). The persistence of different reproductive modes within a single short-generation cnidarian species provides us with the opportunity to study their reproductive strategies and survival abilities.

The study presented here examined how medusae of E. dichotoma responded to a typical seawater salinity (35) and to salinities close to the species' tolerance limits, which were estimated in a preliminary study to be 25 and 45 . Based on the principle of optimal resource allocation (Kozłowski 1992; Stearns 1992), we expected to find that being exposed to salinity stress elevates resource requirements and leads to a reduction in the resources available for sexual and asexual reproduction, as well as for survival. Here, we define salinity stress in two ways: (1) experiencing salinities that diverge considerably from typical seawater conditions, which can lead to decreased growth and reproduction rates and, (2) experiencing a change in salinity between the polyp and medusa generation that requires adjustments in ionic regulation. Assuming

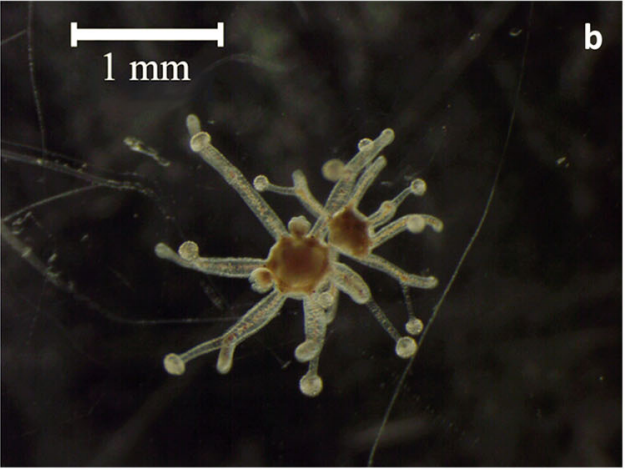

budding medusae. b The medusa reproduces asexually by budding off medusae on the rim of the umbrella or sexually by producing brooded planulae (not shown)

the presence of Muller's ratchet, the mechanism by which damage is passed to successive generations when reproduction is asexual (Felsenstein 1974), we expected to observe gradual deterioration in medusae with each generation. We also expected to find that salinity affected the medusae's reproduction rates and reproductive mode (sexual vs. asexual). This expectation was based on previous research on other budding hydromedusae (Kawamura and Kubota 2008) and the effects of different stress factors on the reproduction of E. dichotoma (Schierwater and Hadrys 1998).

\section{Materials and Methods}

\section{Culture Conditions}

The original stem culture of Eleutheria dichotoma was collected by Schierwater from Banyuls-sur-Mer on the
Fig. 2 Life cycle of Eleutheria dichotoma. Medusae, the hydroid colony, and the planula larva are not plotted on the same scale. A planula larva settles on a solid substrate and metamorphoses into a primary polyp. The primary polyp then starts a hydroid colony, which comprises a system of stolons (hydrorhiza) and polyps (hydranths). Medusa buds develop at the base of each polyp. The hydroid colony reproduces asexually by budding polyps (hydranths) or budding medusae. Primary medusae (medusae released directly by the hydroid colony) first reproduce asexually by budding medusa buds. After 2-4 weeks, sexual reproduction is initiated and planula larvae are released

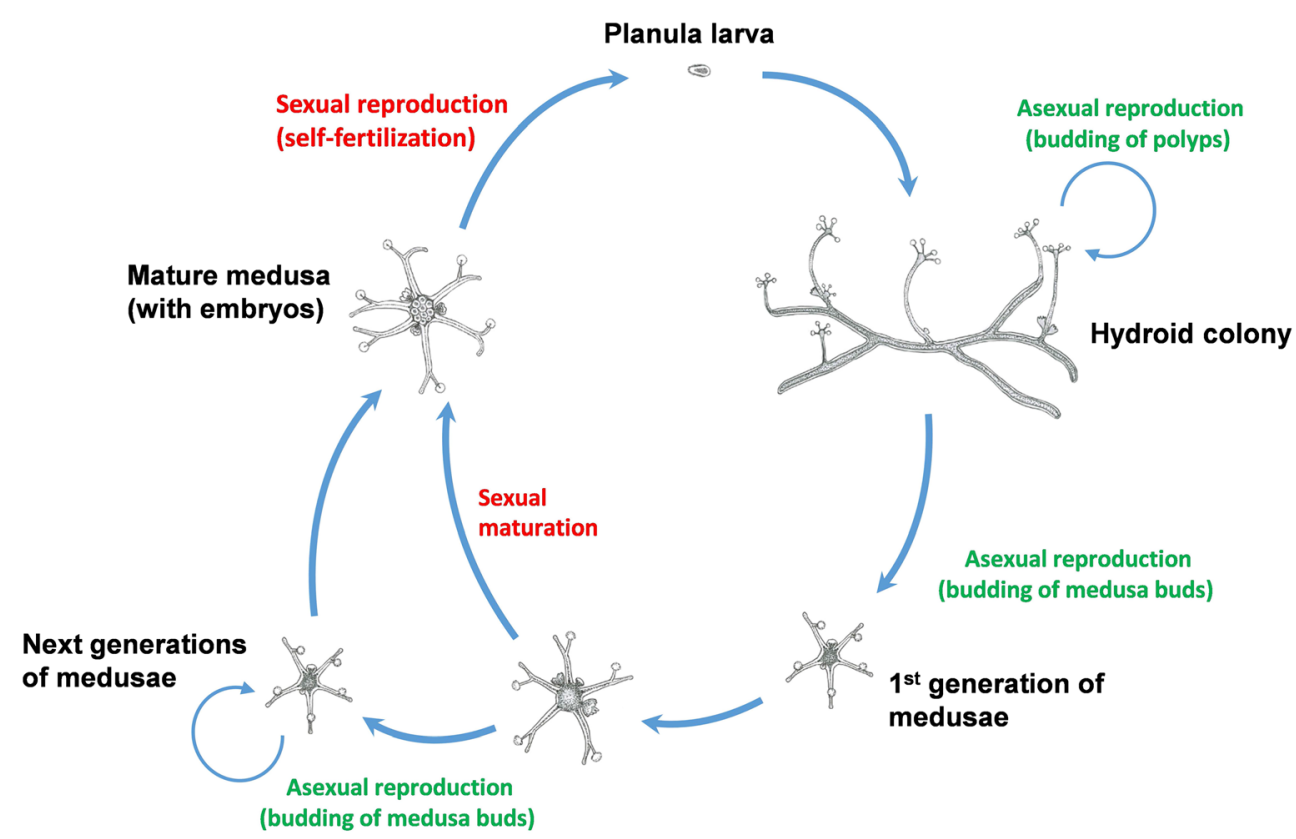


Mediterranean coast of France between 1984 and 1986 (Schierwater and Hauenschild 1990; salinity of the western Mediterranean varies between 36 and 38; Soukissian et al. 2017) and was maintained in the Laboratory of ITZ Ecology and Evolution, Tierärztliche Hochschule Hannover, Germany. In 2010, a sample was donated to the Laboratory of Evolutionary Biodemography at the Max Planck Institute for Demographic Research in Rostock. The laboratory culture was maintained at a temperature of $23{ }^{\circ} \mathrm{C}$, in a 16-h light:8-h dark photoperiod, and a salinity of 35 , which reflects the average salinity of seawater (e.g., Belkin et al. 1998). The culturing medium was prepared using artificial ocean salt (Aquarium Systems Crystal Reefs) and MilliQ water. To reduce the number of foraminifers and the production of biofilm in the culturing dishes, the medium was filtered through paper filters $(0.5 \mu \mathrm{m}$ pore diameter, Roth). Each hydroid colony was reared in $70 \mathrm{~mL}$ of seawater in a glass Boveri dish and fed ad libitum twice a week with nauplii of brine shrimp (Artemia sp.) (see also Dańko et al. 2018 for more details).

\section{Preliminary Study}

A series of salinities (15-50) was used in a preliminary experiment, with a "control" (medium) salinity of 35 . The preliminary experiment showed that in salinities on either side of the control, 25 and 45, the medusae still had buds and survived the entire observational period (45 days). Medusae maintained outside this range (in salinities of 15, 20, and 50) soon died without producing any buds or larvae. Based on these results, three levels of salinity were applied in the main experiment: 25 (low salinity), 35 (medium salinity), and 45 (high salinity). The lowest salinity reflects conditions that may occur after heavy rain or near the mouth of a river, while the highest salinity reflects conditions in isolated, shallow lagoons or tidepools exposed to evaporation (Metaxas and Scheibling 1993).

\section{Preparation of Experimental Hydroid Colonies}

A hydroid colony was raised and cultured for 4 months (JulyOctober 2014) in standard conditions (temperature $23{ }^{\circ} \mathrm{C}$, salinity 35 ). The colony was then cut into three similar fragments, each containing four hydranths. Each fragment was randomly assigned to one of three salinities $(25,35,45)$ in which it would grow a new colony. In order to increase the number of hydranths in colonies, each hydroid colony was fed three times a week with Artemia sp. nauplii ad libitum. In the week before the experiment, the feeding regime was reduced to twice a week. One newly grown colony from each of the three salinity regimes $(25,35$, and 45$)$ was randomly selected to serve as a source of experimental medusae. The medusae used to initiate the experimental treatments were assembled between October and December 2014. By using this approach, we avoided the possibility that medusa bud production varied between experimental colonies because the reproductive activity of the hydroid colonies can differ over the year (e.g., Coma et al. 1998; Bavestrello et al. 2006), The experiment conducted on three generations of medusae was completed in July 2015.

\section{Experimental Set-up}

Before the experiment, all medusae released by hydranths during the acclimation period were removed. From that point forward, the three experimental hydroid colonies were checked every day for newly released medusa buds (primary medusae) and were fed twice a week. One-day-old medusae were photographed and randomly assigned to one of seven experimental treatments (H25M25-3 generations, H25M353 generations, H35M25-3 generations, H35M35-3 generations, H35M45-1 generation, H45M35-1 generation, H45M45-1 generation; salinity experienced by hydroids $(\mathrm{H})$, salinity experienced by medusae (M); more details of the experimental scheme and sample sizes are shown in Fig. 3). In the high salinity treatments (especially in H35M45 and H45M45), medusae reproduced at a much slower rate; therefore, we were unable to collect enough medusae to continue the experiment beyond the first generation.

Medusae were reared individually in $9.5 \mathrm{~mL}$ of seawater in single wells of six-well polycarbonate culture plates with transparent covers to minimize evaporation. They were fed three or four Artemia sp. nauplii twice a week. Seawater changes were performed once a week by moving medusae to the plates with newly prepared seawater. The levels of the medium in the plates with medusae were checked three times a week. In some cases, moderate evaporation was observed in individual wells. When a well was identified as having a low volume due to evaporation, the medium was fully exchanged. Any medusae that died in these conditions (12\% of replicates lost) were treated as lost (right censoring, see also statistical methods). In addition, medusae were checked under a dissecting microscope three times a week for newly released buds and/or planula larvae. The buds and larvae were counted and removed. The first buds that fully separated from the primary medusae initiated the second generation. The same procedure was used to initiate the third generation. The newly produced medusae of the first, second, and third generations were photographed. The diameter of the umbrella (the distance between the two opposite ocelli) and the diameter of the buds developing on the medusae were measured using software ImageJ (NIH). These measurements were, in turn, used to calculate the area of the medusae (see "Statistical Methods" and ESM Fig. A1).

Changes in the morphology of the medusae over their lifespans were documented. Six medusae of the first generation from each experimental cohort were photographed once a 


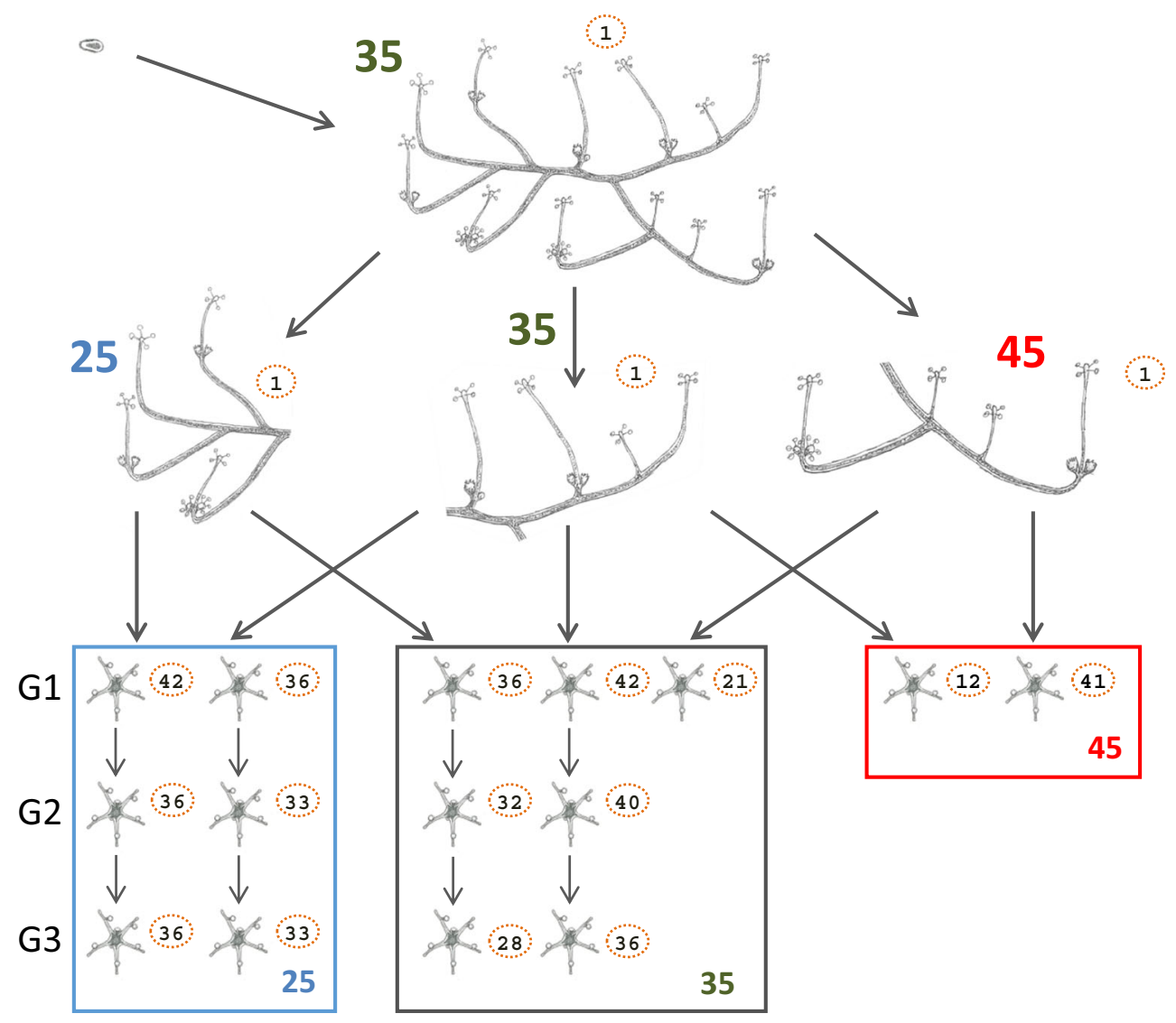

Fig. 3 Experimental setup: Experimental protocol to test the effects of salinity on the reproduction and survival of the hydrozoan Eleutheria dichotoma. One hydroid colony was divided into three standardized fragments with four hydranths (polyps) each. Each fragment was then acclimated to a different salinity (low 25 , medium 35 , or high 45 ) and formed a new colony. The medusae assembled from the hydroid colonies reared in marginal salinities (low or high) were either maintained in the same salinities (H25M25 and H45M45; where H is the salinity experienced by the hydroid colony, and $\mathrm{M}$ is the salinity experienced by medusae), or were transferred to medium salinity conditions (regimes H25M35 and H45M35). The medusae released by the hydroid colonies in medium salinity were either reared in the same conditions (H35M35) or transferred to one of the marginal salinities (H35M25 and H35M45). There was no transfer of the medusae from low to high salinity conditions. G1, G2, and G3 are subsequent generations of medusae. The numbers of replicates are placed in the dotted circles. See the methods section for further details

fully developed embryos and/or medusae that released planulae for the first time were treated as sexually mature. Ages at which medusae reached asexual and sexual maturation, as well as ages at death, were considered time-to-event data. We analyzed these data using methods typical for survival analysis. The data were visualized using a Kaplan-Meier estimator of survival (or the inverse of it for the maturity data) (Kaplan and Meier 1958). A medusa could be classified as lost from the study for two main reasons: (1) a laboratory accident, like water evaporation, occurred; or (2) a medusa was absorbed by a larger medusa bud of the same individual. Such losses were considered right censored (Klein and Moeschberger 2010; Kleinbaum and Klein 2012). We assumed that all losses occurred in the middle of an interval between two consecutive observations.

To analyze age at maturity, we used a semi-parametric test: the Cox proportional hazard model (survival R-package; Therneau and Grambsch 2000). The proportional hazard 
assumption was tested visually by inspecting the log cumulative hazard $(\log (-\log [$ Survivorship] $)$ plots for each combination of salinity and generation. The most parsimonious models were selected using a progressive hierarchical likelihood ratio test. In this test, we started with a model with no interactions between the categorical predictors, but with all the main effects present. We then sequentially added the interactions and tested their significance. As the proportional hazard assumption was clearly violated for the survival data, we avoided using Cox regression, and instead applied two nonparametric tests for the equality of survival distributions: the log-rank test (survival R-package: Therneau and Grambsch 2000) and the Gehan-Breslow-Wilcoxon test (coin R-package: Hothorn et al. 2008). The log-rank test is most powerful when the hazard ratios are proportional, but it is mainly sensitive to late-occurring events. The Gehan-Breslow-Wilcoxon test is more powerful than the log-rank test when the proportional hazard assumption is not fulfilled, but it gives more weight to early events (Martinez and Naranjo 2010). We used the Gehan-Breslow-Wilcoxon test as an additional test because it can partially complement the log-rank test.

We observed that the salinity experienced by the hydroid colonies had no or minimal effects on the survival of medusae in consecutive generations, and that there were still no effects when the generations were pooled (see ESM Table A1). Therefore, we combined the time-to-event data from experiments in which the medusae experienced the same conditions independent of the conditions experienced by hydroid colonies. The effects of the generation of the medusae for the timeto-event data were analyzed separately for each salinity. The effects of salinity were analyzed separately for each generation of medusae, and for combined generations. The $p$ values were corrected for multiple-comparison bias using Holm's method.

Asexual and sexual daily reproduction rates were analyzed using general linear models (GLM). To avoid biased statistical inferences caused by over-dispersion, we used the negative binomial regression (MASS R-package; Venables and Ripley 2002). In both sets of models, the sum of the released medusae and/or larvae was set as the dependent variable, the natural logarithm of individual exposures (individual days lived) was used as the offset, and the natural logarithm was set as the link function. We removed the salinity 45 treatments (for both hydroid colonies and medusae) from the reproduction rate analyses because these treatments contained groups for which there were no counts, and for which there were no data for the second and third generations (see "Experimental Set-up"). A comparison of the H35M35 control group (H is the salinity experienced by hydroid colony, $\mathrm{M}$ is the salinity experienced by medusae) with the H45M35 group was done separately using a negative binomial model. The most parsimonious model was selected from the partially nested models constructed from different combinations of main effects and their interactions by minimizing the Akaike information criterion (AIC) (Burnham and Anderson 2003). Insignificant interactions were dropped from the model.

The age-specific reproduction rates were smoothed by fitting one-dimensional Poisson penalized splines (MortalitySmooth R-package; Camarda 2012) that accounted for over-dispersion. The log of exposures was set as an offset, and the smooth parameter lambda was selected via the minimization of the BIC (Bayesian information criterion). The standard errors of the reproduction rates were calculated from the standard errors of the smoothed log rates. The $95 \%$ confidence intervals were calculated from the standard errors.

To estimate the sizes of 1-day-old medusae, we analyzed the area of the body of each individual, calculated as:

Area $=2.622 \times$ Umbrella diameter $^{2.26}+\Sigma\left(0.265 \times\right.$ Bud diameter $\left.^{2.239}\right)$

where umbrella diameter is the distance between two opposite ocelli on the aboral side of the umbrella, and bud diameter is the diameter of the buds developing on the rim of the umbrella (ESM Fig. A1; Schierwater 1989). The data were analyzed by linear regression, assuming $\log _{10}$ of the area as a dependent variable. The $\log _{10}$ transformation was necessary to obtain normally distributed residuals.

\section{Results}

\section{Ages at First Asexual and Sexual Reproduction}

Salinity influenced the age at which the first medusa bud was released by a medusa (first asexual reproduction). The median age at asexual maturity for all medusae reared in medium salinity (35), for the pooled effects of salinity experienced by hydranths (excluding H45M35 treatment - hydroid colony (H) reared at salinity 45 , medusae (M) reared at salinity 35 ), was estimated at 11 days in G1 (11.5 days for H25M35G1 and 10.5 days for H35M35G1), 18.5 days in G2 (20 days for $\mathrm{H} 25 \mathrm{M} 35 \mathrm{G} 2$ and 18.5 days for $\mathrm{H} 35 \mathrm{M} 35 \mathrm{G} 2$ ), and 26 days in G3 (29.5 days for H25M35G3 and 22.5 days for H35M35G3). Medusae in low salinity (25) generally produced their first bud (became asexually mature) at a rate that was roughly three times faster than that of medusae reared in medium salinity (35) (Table 1). This result is supported by the following differences between the estimated median days at maturity for the pooled effects of salinity experienced by hydranths: -2.25 days for G1 ( -3 days difference between H25M25G1 and H35M35G1), -7 days for G2 (- 7 days difference between $\mathrm{H} 25 \mathrm{M} 25 \mathrm{G} 2$ and $\mathrm{H} 35 \mathrm{M} 35 \mathrm{G} 2$ ), and - 13 days in $\mathrm{G} 3$ ( -9.5 days difference between H25M25G2 and H35M35G2). We found that the generation number had a significant effect on the rate at which individuals became 
Table 1 Asexual maturity of hydromedusae Eleutheria dichotoma reared in different salinities; results of the fitted Cox proportional hazard regression models

\begin{tabular}{llllrr}
\hline & Coef & $\exp (\mathrm{coef})$ & SE & \multicolumn{1}{c}{$z$} & $\operatorname{Pr}(>|z|)$ \\
\hline Hydroid colony (salinity =25) & -0.0955 & 0.9089 & 0.1010 & -0.95 & 0.344 \\
Medusa (salinity =25) & 1.0814 & 2.9488 & 0.1108 & 9.76 & $<0.001$ \\
Generation (G2) & -0.6404 & 0.5271 & 0.1221 & -5.25 & $<0.001$ \\
Generation (G3) & -1.2484 & 0.2870 & 0.1316 & -9.48 & $<0.001$ \\
\hline
\end{tabular}

The interactions were non-significant and were dropped from the models. The treatments with the hydroid colonies and the medusae that experienced high salinity were excluded from this analysis (see "Statistical Methods"). The reference was set as H35M35G1 (hydroid colony reared in salinity 35 (H35), medusae reared in salinity 35 (M35), first generation (G1) asexually mature. The rate of reaching asexual maturity decreased about twofold between each of the consecutive generations (Table 1). In the cohorts with medusae reared in high salinity (45), only $20 \%$ of individuals reached asexual maturity in the H45M45 treatments, and none reached asexual maturity in the H35M45 treatments (Fig. 4a). There was no significant difference in the time to asexual maturity between the H45M35 and the H35M35 treatments (log-rank: Chi square $=0.64, p=0.423$; Gehan-Breslow: Chi square $=2.36$, $p=0.124 ; 3.75$ days of difference between medians). This result, along with the findings presented in Table 1, show that the salinity experienced by hydranths had no significant effect on how quickly medusae became asexually mature (Table 1).

Salinity affected the age at which embryos were observed inside medusa, and/or the age at which the first planula was released. The median age at sexual maturity for medusae reared in medium salinity (35), for the pooled effects of salinity experienced by hydranths (excluding H45M35 treatment), was 41 days in G1 (44.5 days for H25M35G1 and 34 days for H35M35G1), 38 days in G2 (44.5 days for H25M35G2 and 33 days for $\mathrm{H} 35 \mathrm{M} 35 \mathrm{G} 2$ ), and 28 days in $\mathrm{G} 3$ (also 28 days for H25M35G3 and for H35M35G3). The rate at which medusae reached sexual maturity was generally about three times slower (0.34) in low salinity than in medium salinity (Table 2). This result is supported by the following differences between the estimated median days at maturity for the pooled effects of salinity experienced by hydranths: 37 days for G2 and 27.5 days for G3 (34 days difference between H25M25G3 and H35M35G3). This difference could not be estimated for $\mathrm{G} 1$ because most individuals in pooled H25M25G1 and H35M25G1 treatments died before reaching maturity. In the second $\mathrm{H} 25 \mathrm{M} 25$ generation, fewer than half of the individuals reached asexual maturity. However, the rate of sexual maturity increased by $32 \%$ from G1 to G2. This rate was even higher in G3 (roughly twice as high as in G1) (Table 2). None of the medusae matured sexually in the highest salinity (Fig. 4d). There was also no difference in the rate of reaching sexual maturity in the H45M35 and the H35M35 treatments (log-rank: Chi square $=0.01, p=0.924$; Gehan-Breslow: Chi square $=0.25, p=0.616,1.25$ days of difference between medians).
Interestingly, we observed that the salinity experienced by the hydroid colonies had a significant effect on the age at which the first larva was released (Table 2), but not on the age at which the first bud was released (Table 1). The medusae released by the hydroid colonies in low salinity (25) reached sexual maturity at a rate that was $27 \%$ slower than that of the medium salinity group (Table 2).

\section{Asexual Reproduction Rates (Medusa Budding Rates)}

Rates of asexual reproduction were highest in low salinity (Fig. 5a-c; Table 3). The predicted rates were highest in the first generation of the H25M25 and H35M25 treatments: 0.96 and 0.97 buds medusa $^{-1}$ week $^{-1}$, respectively $(0.88$ and 0.90 in G2 and 0.79 and 0.81 in G3). The salinity experienced by hydroid colonies, as well as their interaction with the salinity experienced by medusae, had minor effects on the budding rates (Table 3). Medusae that detached from hydroid colonies in low salinity and were subsequently reared in medium salinity (H25M35) had slightly higher predicted budding rates than medusae from the H35M35 treatment ( 0.67 vs. 0.59 buds medusa $^{-1}$ week $^{-1}$ in $\mathrm{G} 1,0.50$ vs. 0.44 in $\mathrm{G} 2$, and 0.44 vs. 0.39 in G3) (Fig. 5; Table 3). We found no differences in the budding rates of the H45M35 and H35M35 groups in the first generation $(z=-0.89, p=0.374$; observed mean: 0.62 buds medusa $^{-1}$ week $^{-1}$ for the combined H45M35 and H35M35 groups). The budding rates decreased with each generation in all treatments (Fig. 5b, c; Table 3).

\section{Sexual Reproduction Rates (Planula Production Rates)}

The salinities experienced by the hydroid colonies and the medusae had significant effects on the planula production rates (Fig. 5d-f; Table 4), with the highest predicted rates observed in medium salinity H35M35 (0.64 planulae medusa $^{-1}$ week $^{-1}$ in G1, 0.62 in G2, and 0.59 in G3). Medusae that experienced low salinity at the beginning of bud development and/or later in life had lower predicted rates of sexual reproduction. (H25M35, 0.41 planula medusa $^{-1}$ week $^{-1}$ in $\mathrm{G} 1,0.39$ in $\mathrm{G} 2$, and 0.37 in G3; $\mathrm{H} 25 \mathrm{M} 25,0.06$ in $\mathrm{G} 1,0.11$ in G2, and 0.17 in G3; H35M25, 

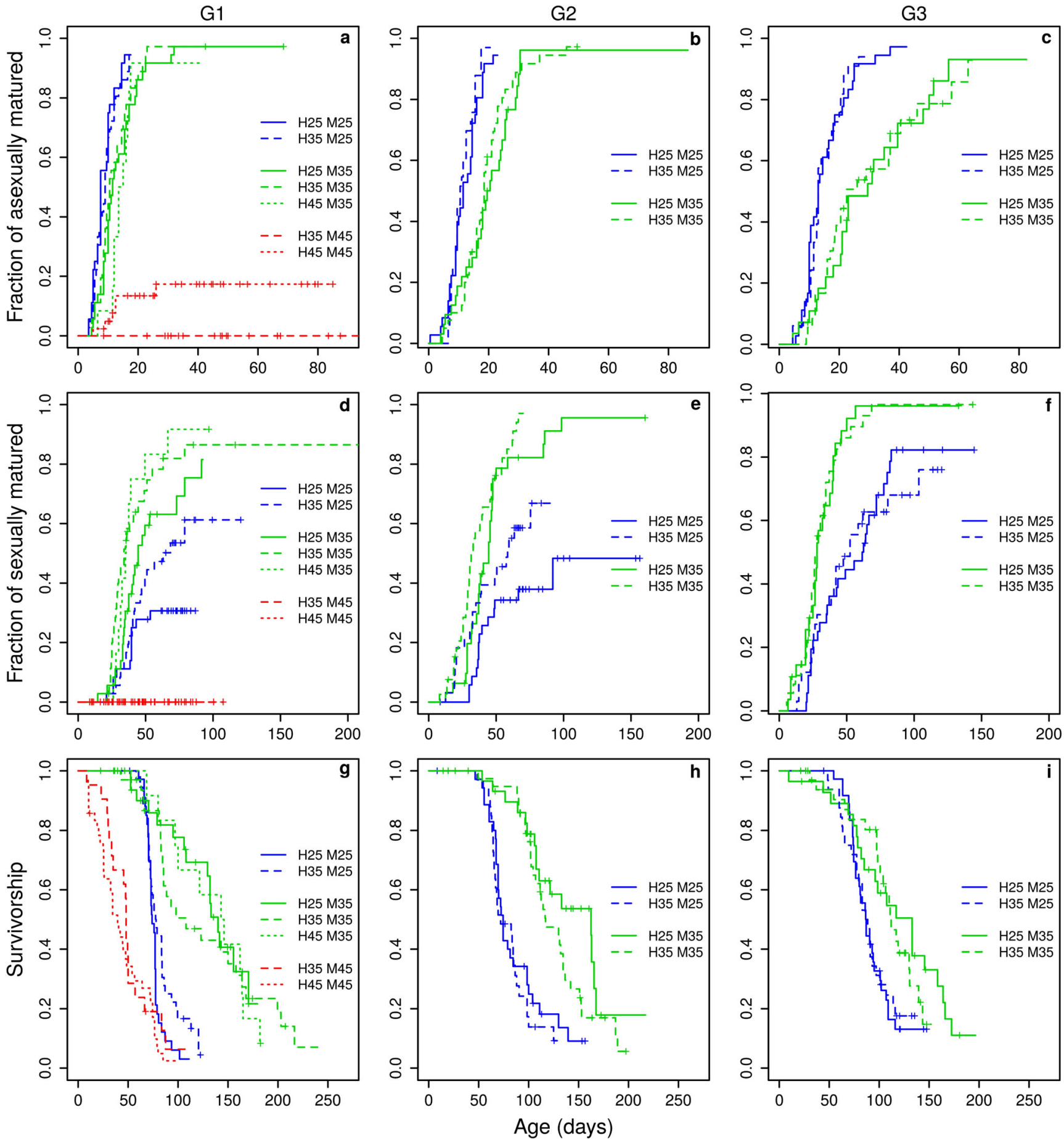

Fig. 4 Asexual maturity, sexual maturity, and survivorship in three generations of medusae Eleutheria dichotoma maintained in different salinities. The first two rows represent the inverse of Kaplan-Meier estimators of asexual $(\mathbf{a}-\mathbf{c})$ and sexual $(\mathbf{d}-\mathbf{f})$ maturity. The third row $(\mathbf{g}-\mathbf{i})$ represents the Kaplan-Meier estimator of survival of medusae exposed to different salinities. The line patterns represent the different salinities experienced by the hydroid colonies; the colors represent the different

0.10 in G1, 0.17 in G2, and 0.26 in G3). Medusae in high salinity did not produce planulae. There were no differences in the planula production rates in the H45M 35 and the H35M 35 salinities experienced by the medusae; and the columns (G1, G2, and G3) represent different generations of the medusae. Medusae from the H35M35 treatment were released by the hydroid colony in salinity 35 , and were maintained in the same salinity. Medusae from the H35M25 treatment were released by the hydroid colonies in salinity 35 , and were transferred to salinity 25 . The other regimes should be read analogically

groups of the first generation $(z=-1.06, p=0.288$; observed mean, 0.66 planula medusa ${ }^{-1}$ week $^{-1}$ for combined H45M35 and the H35M35 groups). 
Table 2 Sexual maturity of hydromedusae Eleutheria dichotoma from different salinities; results of the fitted Cox proportional hazard regression models

\begin{tabular}{llllrr}
\hline & Coef & $\exp ($ coef $)$ & SE & \multicolumn{1}{c}{$z$} & $\operatorname{Pr}(>|z|)$ \\
\hline Hydroid colony (salinity $=25)$ & -0.3142 & 0.7303 & 0.1183 & -2.66 & 0.008 \\
Medusa (salinity =25) & -1.0686 & 0.3435 & 0.1239 & -8.63 & $<0.001$ \\
Generation (G2) & 0.2799 & 1.3230 & 0.1476 & 1.90 & 0.058 \\
Generation (G3) & 0.7003 & 2.0144 & 0.1467 & 4.77 & $<0.001$ \\
\hline
\end{tabular}

The interactions were non-significant and were dropped from the models. The treatments with the hydroid colony and the medusae that experienced high salinity were excluded from this analysis (see "Statistical Methods"). The reference was set as H35M35G1 (hydroid colony reared in salinity 35, medusae reared in salinity 35 , first generation)
The larval production rate decreased with each generation among medusae reared in medium salinity, but increased with each generation among medusae reared in low salinity (Fig. $5 \mathrm{e}, \mathrm{f})$, due to a significant interaction between salinity and generation (Table 4).

\section{Age-Specific Reproduction Rates}

The three generations of medusae maintained in low salinity (Fig. 6a) had qualitatively very similar age-specific patterns of asexual reproductive rates (medusa budding rates) that
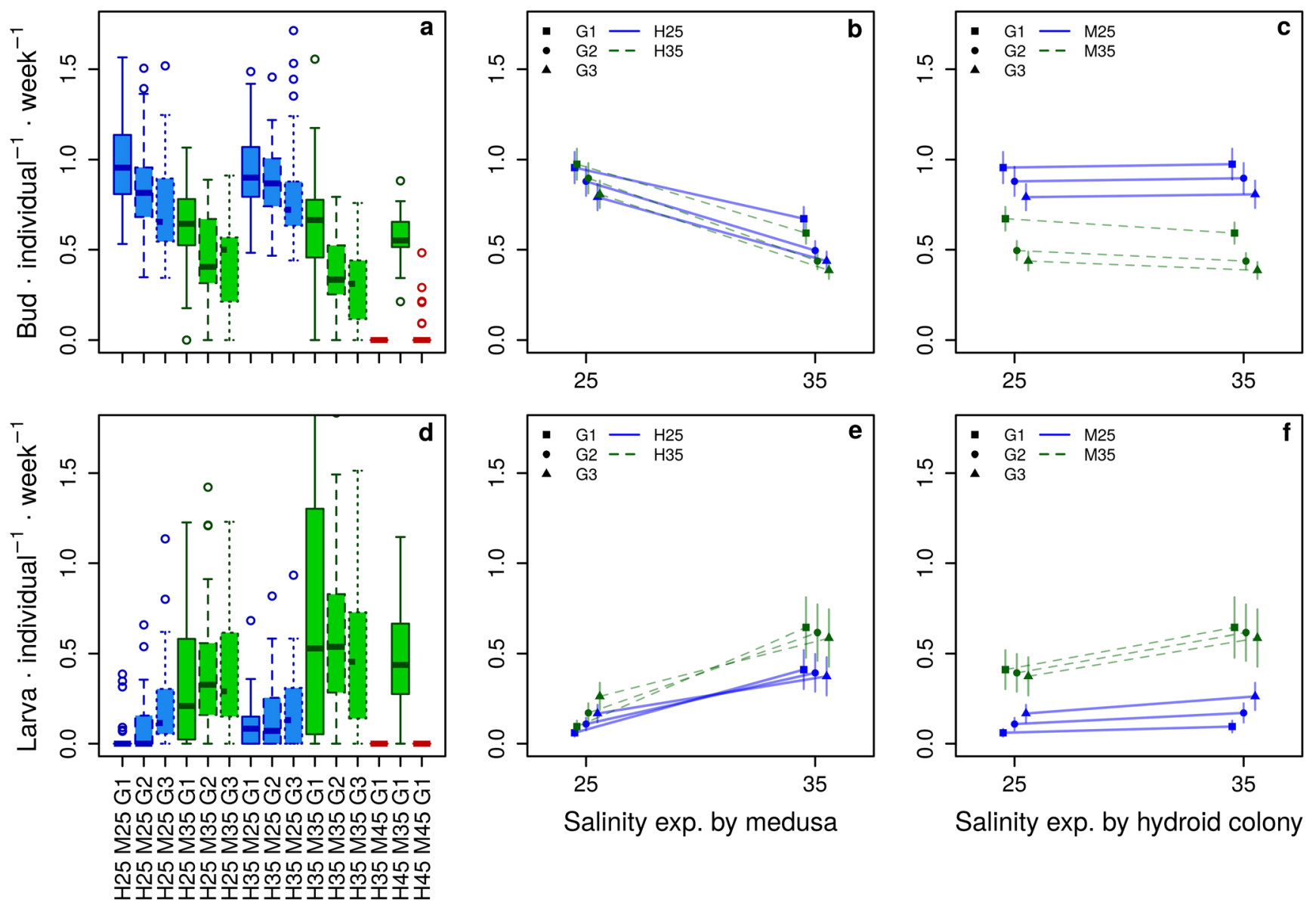

Salinity exp. by medusa

Salinity exp. by hydroid colony

Fig. 5 The rates of bud production (top, a-c) and larva production (bottom, d-f) in three generations of hydromedusa Eleutheria dichotoma maintained in different salinities. a, $\mathbf{d}$ Box plots of data; $\mathbf{b}, \mathbf{e}$ predictions of corresponding models shown from the perspective of the effect of the salinity experienced by medusae; c, f predictions of corresponding models shown from the perspective of the effect of the salinity experienced by the hydroid colony. Estimated daily rates were converted to weekly rates. Medusae from the H35M35 treatment were released by the hydroid colony in salinity 35 and were maintained in the same salinity. Medusae from the H35M 25 treatment were released by the hydroid colony in salinity 35 and were transferred to salinity 25 . The other regimes should be read analogically 
Table 3 Asexual reproduction rate; results of the most parsimonious model, which was fitted assuming a negative binomial distribution

\begin{tabular}{lrllrr}
\hline & Coef & exp (coef) & SE & \multicolumn{1}{c}{$z$} & $\operatorname{Pr}(>|z|)$ \\
\hline Intercept) & -2.4694 & 0.0846 & 0.0507 & -48.66 & $<0.001$ \\
Hydroid colony (salinity =25) & 0.1261 & 1.1344 & 0.0542 & 2.33 & 0.020 \\
Medusa (salinity = 25) & 0.4979 & 1.6453 & 0.0679 & 7.33 & $<0.001$ \\
Generation (G2) & -0.3050 & 0.7371 & 0.0625 & -4.88 & $<0.001$ \\
Generation $(G 3)$ & -0.4303 & 0.6503 & 0.0693 & -6.21 & $<0.001$ \\
Hydroid colony $\times$ medusa (salinity =25) & -0.1457 & 0.8644 & 0.0717 & -2.03 & 0.042 \\
Medusa $\times$ generation $($ salinity = 25, G2) & 0.2216 & 1.2481 & 0.0845 & 2.62 & 0.009 \\
Medusa $\times$ generation $($ salinity = 25, G3) & 0.2419 & 1.2737 & 0.0898 & 2.69 & 0.007 \\
\hline
\end{tabular}

The highest applied salinities were excluded from this analysis (see "Statistical Methods"). The reference was set as $\mathrm{H} 35 \mathrm{M} 35 \mathrm{G} 1$ (hydroid colony reared in salinity 35 , medusae reared in salinity 35 , first generation) differed only in magnitude from the first peak (the rate was highest in the first generation, was lower in the second generation, and was negligible in the third generation). After reaching their peak level of bud production, medusae continued budding at a roughly constant rate until the end of life in G1 and G2 and at a rate that seemed to increase again in G3. This was not the case for larval production, which was occurring at a very low rate, and ceased long before the end of life (Fig. 6c).

In medium salinity (35), both medusa budding and planula production rates were highest in the first generation (Fig. $6 \mathrm{~b}, \mathrm{~d})$. The initial peak in the larval production rate in $\mathrm{G} 1$ was about twice that of the highest medusa budding rate. The larval production rate decreased with age, and, as in the low-salinity treatments, ceased long before death (Fig. 6d).

\section{Survival}

The salinities experienced by hydroid colonies had no effect on the survival of medusae (ESM Table A1), but the salinity experienced by medusae significantly affected their survival. For medusae, the highest survival rate was in medium salinity and the lowest survival rate was in high salinity (Fig. 4g-i). The differences in the survival rates associated with different salinities were significant in each generation (the first three rows of Table 5). The effect of generation was analyzed separately for low and medium salinities. Medusae reared in high salinity were not included in the generation analysis due to the lack of second and third generations (see experimental set-up). We observed a significant effect of generation on the survival of medusae reared in low salinity, but not in medium salinity (the last two rows of Table 5). The third generation of medusae reared in low salinity had slightly lower rates of survival than the other generations. For the pooled effects of salinity experienced by hydranths, the following median ages at death were estimated: M25G1, 76 days; M25G2, 73.5 days; M25G3, 86.75 days; M35G1, 132 days (M45M35G1 excluded); M35G2, 131 days; M35G3, 117 days; and M45G1, 45 days; for the pooled effects of salinity experienced by hydranths and pooled generations, the following median ages at death were estimated: M25, 77.5 days and M35, 130 days.

\section{Sizes of 1-Day Old Primary Medusae}

The log of the area of primary medusae (first generation of medusae released by hydranths) was largest in the H35M35 treatment (the reference group in regression analysis, Table 6); however, not all of our results were significant. The area of medusae was significantly smaller in the highest salinity $(17 \%$ smaller than in the reference group) and in the second generation (7\% smaller in the lowest salinity than in the reference group).
Table 4 Sexual reproduction rate. Results of the most parsimonious model, which was fitted assuming a negative binomial distribution

\begin{tabular}{llllrr}
\hline & Coef & exp (coef) & SE & $z$ & $\operatorname{Pr}(>|z|)$ \\
\hline Intercept) & -2.3861 & 0.0920 & 0.1325 & -18.01 & $<0.001$ \\
Hydroid colony (salinity =25) & -0.4489 & 0.6383 & 0.1109 & -4.05 & $<0.001$ \\
Medusa (salinity =25) & -1.9134 & 0.1476 & 0.2084 & -9.18 & $<0.001$ \\
Generation (G2) & -0.0449 & 0.9561 & 0.1707 & -0.26 & 0.793 \\
Generation (G3) & -0.0949 & 0.9095 & 0.1777 & -0.53 & 0.593 \\
Medusa $\times$ generation (salinity = 25, G2) & 0.6309 & 1.8793 & 0.2840 & 2.22 & 0.026 \\
Medusa $\times$ generation $($ salinity =25, G3) & 1.1107 & 3.0365 & 0.2813 & 3.95 & $<0.001$ \\
\hline
\end{tabular}

The highest applied salinities were excluded from this analysis (see "Statistical Methods"). The reference was set as $\mathrm{H} 35 \mathrm{M} 35 \mathrm{G} 1$ (hydroid colony reared in salinity 35 , medusae reared in salinity 35 , first generation) 
Fig. 6 Age-specific asexual and sexual reproductive rates for the medusae maintained in low hydroid colony/medusa salinity $(\mathbf{a}, \mathbf{c})$ and medium hydroid colony/medusa salinity $(\mathbf{b}, \mathbf{d})$. G1, G2, and G3 are medusae from subsequent generations (first, second, and third)
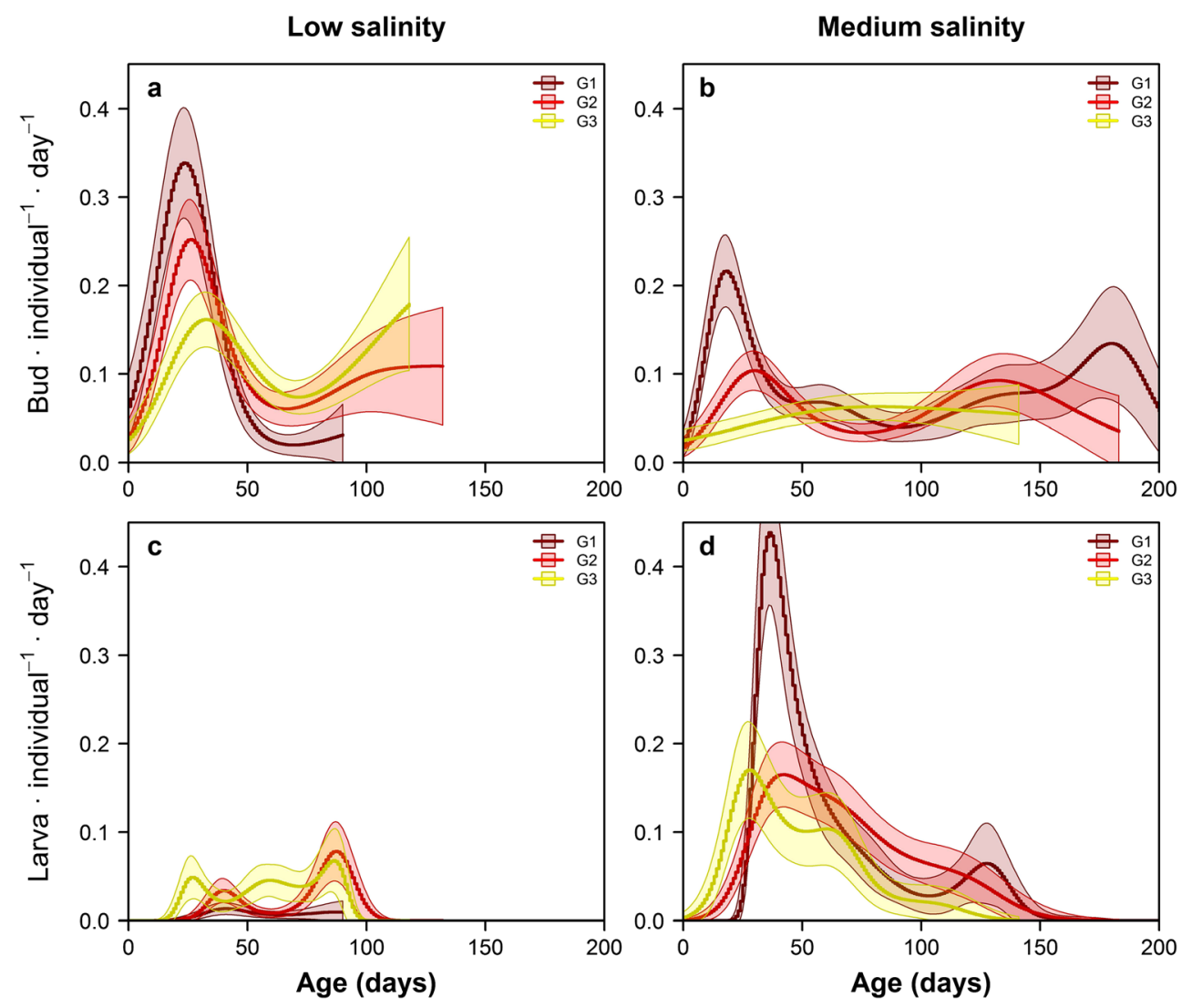

\section{Discussion}

Our results show that the level of salinity a hydroid colony is exposed to may affect the onset of reproduction and the reproductive rate of medusae. Medusae that detached from a low-salinity hydroid colony and were transferred to medium salinity conditions reached sexual maturity later and had lower larval production rates than the H35M35 control group. Conversely, the asexual reproduction of these medusae increased. Some research (e.g., Ma and Purcell 2005 on Moerisia lyonsi; and Dańko et al. in prep. on Eleutheria dichotoma) has suggested that hydroid colonies are more tolerant of variation in environmental conditions, including in salinity and temperature, than medusae. This might be because hydroid colonies have mechanical protection (a perisarc covering a system of stolons); a strong capacity for regeneration (Dańko et al. 2015); or protective molecular mechanisms, such as a high expression of the foxO transcription factor (Boehm et al. 2012), that can activate heat shock proteins (e.g., Kim et al. 2005; Donovan and Marr 2016). It can thus be hypothesized that the connection between medusa buds and hydranths might have a protective effect on the buds by providing additional nutrients, or even stem cells like those in Hydra sp. in adverse conditions (Wittlieb et al. 2006). Nonetheless, as medusae grow from a bud attached to a hydranth, they initially experience the same environmental conditions, which could affect their trajectories later in life.

We showed that asexual reproduction of E. dichotoma is more common in low salinity (25). Medusae reared in these conditions initiated budding earlier ( 7.5 median days in $\mathrm{H} 25 \mathrm{M} 25 \mathrm{G} 1$ vs. 10.5 median days in H35M35G1; both values increased with each generation), and generally had higher budding rates than in medium salinity $\left(0.96\right.$ buds medusa $^{-1}$ week $^{-1}$ for $\mathrm{H} 25 \mathrm{M} 25 \mathrm{G} 1$ vs. 0.59 buds medusa ${ }^{-1}$ week $^{-1}$ for H35M35G1; both rates decreased with each generation). Importantly, increased asexual reproduction resulted in delayed sexual maturity and lower rates of larval production. Kawamura and Kubota (2008) observed that the hydromedusa, Proboscidactyla ornata, reared at $20^{\circ} \mathrm{C}$ or $23^{\circ} \mathrm{C}$ had a budding rate that was higher at a salinity of 34 than at 28 or 31 . In general, the asexual budding of medusae may play a role in extending the planktonic lifespan of a medusa morph, which is shorter than that of a hydroid colony (Kawamura and Kubota 2008). The occurrence of asexually reproducing medusae is rather common in hydromedusae (Boero et al. 2002) and has been observed in at least 50 of 842 species (except siphonophores; Bouillon 1994 after Kawamura and Kubota 2008). However, simultaneous asexual and sexual reproduction in medusae appears to be rare (Bouillon 1994 after Kawamura and Kubota 2008). More research on the effect of salinity on sexual and asexual reproduction in medusae is needed. 
Table 5 Comparison of the survival distributions for the different generations and salinities experienced by the medusae

Group Compared sub-groups $d f$ Log-rank stat Log-rank $p$ Holm's log-rank $p$ Gehan-Breslow stat Gehan-Breslow $p$ Holm's Gehan-Breslow $p$

\begin{tabular}{|c|c|c|c|c|c|c|c|c|}
\hline G1 & M25, M35, and M45 & 2 & 88.87 & 0.0000 & 0.0000 & 110.99 & 0.0000 & 0.0000 \\
\hline G2 & M25 and M35 & 1 & 5.65 & 0.0000 & 0.0000 & 6.46 & 0.0000 & 0.0000 \\
\hline G3 & M25 and M35 & 1 & 3.32 & 0.0009 & 0.0027 & 3.31 & 0.0009 & 0.0027 \\
\hline M25 & $\mathrm{G} 1, \mathrm{G} 2$, and $\mathrm{G} 3$ & 2 & 9.92 & 0.0070 & 0.0140 & 8.85 & 0.0120 & 0.0240 \\
\hline M35 & $\mathrm{G} 1, \mathrm{G} 2$, and $\mathrm{G} 3$ & 2 & 3.61 & 0.1646 & 0.1646 & 3.17 & 0.2052 & 0.2052 \\
\hline
\end{tabular}

Two methods were used: log-rank and Gehan-Breslow. To avoid bias caused by multiple comparisons, the $p$ values were adjusted using Holm's method. M25, M35, and M45 are medusae maintained in salinities 25, 35, and 45, respectively. G1, G2, and G3 are subsequent generations of medusae

The effect of salinity on asexual reproduction in polyps has received more attention than the effect of salinity on sexual reproduction in medusae. In polyps in low salinity, increased asexual reproduction through the budding of more medusae has been observed in some estuarine species, such as the hydrozoan Moerisia lyonsi (e.g., Ma and Purcell 2005) and cubozoan Carybdea sp. (Canepa et al. 2014). In contrast, low salinity conditions have been shown to decrease asexual reproduction in the polyps of other cnidarians (e.g., Rippingale and Kelly 1995) or to have no effect (e.g., Willcox et al. 2007). Asexual reproduction in medusae and asexual reproduction in polyps may play different roles in the ecology of the organism. Nonetheless, asexual reproduction generally allows for rapid propagation and the colonization of new environments (e.g., Schlesinger et al. 2010; Canepa et al. 2014), as it is a fast developmental process that appears to be dependent on the proliferative potential of somatic cells, and can be related to regeneration (Fautin 2002; Tanaka and Reddien 2011; Dańko et al. 2015).

We observed that medium salinity conditions (35) were more favorable than higher or lower salinity conditions for sexual reproduction, larval development, and survival in E. dichotoma. This is likely because a salinity of 35 is standard for sea water, and is close to the salinity of the western Mediterranean, where these cultures originated. Medusae reared in medium salinity reached sexually maturity the fastest (median, 34 days for H35M35G1) and produced larvae at the highest rate $\left(0.64\right.$ planula medusa $^{-1}$ week $\left.^{-1}\right)$. In contrast, less

Table 6 Effects of salinity and the effects of generation on the log of the area of 1-day-old medusae (area was measured in $\mu \mathrm{m}^{2}$ )

\begin{tabular}{llllll}
\hline & Coef & $\exp ($ coef $)$ & $\mathrm{SE}$ & $t$ & $\operatorname{Pr}(>|t|)$ \\
\hline (Intercept) & -0.6826 & 0.5053 & 0.0243 & 219.19 & 0.0000 \\
Salinity (H25M25) & -0.0227 & 0.9776 & 0.0264 & -0.86 & 0.3910 \\
Salinity (H45M45) & -0.1890 & 0.8278 & 0.0613 & -3.08 & 0.0024 \\
Generation (G2) & -0.0772 & 0.9257 & 0.0305 & -2.53 & 0.0121 \\
Generation (G3) & -0.0472 & 0.9539 & 0.0335 & -1.41 & 0.1605
\end{tabular}

The reference was set as $\mathrm{H} 35 \mathrm{M} 35 \mathrm{G} 1$ (hydroid colony reared at salinity 35 , medusae reared at salinity 35 , first generation) than half of medusae reared in low salinity (H25M25G1) reached maturity at all, and the reproduction rate of all individuals in this group was about 10 times lower than that of medusae reared in medium salinity $(0.06$ planula medusa $^{-1}$ week $^{-1}$, but increased with each generation). Clearly, sexual reproduction cannot play a role in maintaining genetic diversity in Eleutheria dichotoma because this organism is a simultaneous hermaphrodite. Thus, all of its eggs are fertilized by sperm of the same individual (Hadrys et al. 1990). Medium salinity $(\sim 35)$ is typical of sheltered coastal inlets that are connected to the open sea. In these conditions, a large investment in the production of planula larvae might be advantageous. The flushing process leads to the exchange of water between the tidepools and the shore. Larvae then settle and produce new colonies of environmentally resistant hydroids, which may serve as bridgeheads of colonization. Planulae and polyps of several scyphozoan species are highly tolerant of low salinities, which may be an adaptation to the brackish waters of estuaries (Holst and Jarms 2010). Furthermore, planulae of Eleutheria dichotoma can disperse more widely than the crawling medusae form (Gilchrist 1919; Hirano et al. 2000).

We showed that high salinities negatively affected asexual and sexual maturation as well as the reproductive rates of E. dichotoma. In high salinity, asexual maturation was delayed, the budding rate was lower, and planula production never occurred. The reduced rates of reproduction in these conditions might be partly a consequence of the increased cost of osmotic stress, which results in the organism having less energy for reproduction. In hyperosmotic conditions, cnidarian cells that begin to shrivel can regain water via regulatory volume increases (e.g., in Anemonia sargassensis; Amado et al. 2011). This occurs through the synthesis of osmotically active molecules, such as methylamines, free amino acids, and derivatives and requires energy (Rivera-Ingraham and Lignot 2017). In some cnidarian species, asexual reproduction rates decrease in high salinity conditions (e.g., Purcell et al. 1999), but this effect is often modulated by temperature (e.g., Purcell 2007).

Our results show that under laboratory conditions, salinity may affect the survival of medusae. Salinities that were lower or higher than the reference condition of 35 were found to be 
associated with lower survival. The finding that in low salinity, survival began to decline rapidly just after the peak in asexual reproduction was reached suggests that medusae were making high initial investments in reproduction. These results seem to indicate that there is a trade-off between resource allocation to reproduction and maintenance mechanisms such as osmotic adaptation (e.g., antioxidants) and tissue repairs. Insufficient investments in maintenance can cause damage to accumulate, which may, in turn, result in faster deterioration and senescence. Additionally, at marginal salinities, the accumulation of damage may be accelerated by a high respiration rate, and thus by oxidative stress from free radicals (e.g., Downs et al. 2009; reviewed by Rivera-Ingraham and Lignot 2017). Asexual reproduction may lead to the accumulation of deleterious mutations and damage over generations, which can, in turn, result in a gradual deterioration of the genetic line (Felsenstein 1974; Loewe and Cutter 2008). In medium salinities, some degree of generational deterioration was visible in both asexual and sexual reproductive rates, as well as in delayed asexual maturity with each generation. However, in these conditions, survival was not affected, and time to sexual maturity decreased with each generation. For medusae reared in low salinity, the evidence supporting the deterioration hypothesis was also mixed. On the one hand, medusae reared in low salinity had lower sexual reproduction rates and reached sexual maturity later than other medusae. On the other hand, these medusae reached sexual maturation earlier and produced more larvae with each generation. Alternatively, the gradual shift in reproductive modes observed among these medusae might be a result of adaptation to seasonal changes or to internal rhythms. Hydrozoans are known to have circannual internal rhythms (Reitzel et al. 2013), which can affect the reproductive phases of their hydroid colonies (Bavestrello et al. 2006). Such internal rhythms might be present in medusae of $E$. dichotoma, and could influence their reproductive strategies over the course of a season.

\section{Conclusions}

Changes in life history traits in response to unfavorable salinities can be explained by optimal resource allocation theory. In unfavorable salinities, even an osmoconforming organism is forced to cope with various costs of osmoregulation to prevent death. The resources an individual invests in coping with intracellular osmolarity cannot be used for other aspects of organismal performance. Thus, medusae that are exposed to different salinities tend to express different life history strategies.

We showed that a change in salinity may lead to a shift in reproductive modes. In medium salinity (35), the production rates of medusa buds were similar to the production rates of planula larvae; but in low salinity (25), asexual reproduction rates increased and sexual reproduction rates decreased. Medusae reared in low salinity (25) shifted their reproductive mode and had increased mortality, possibly due to allocation tradeoffs. The increased investment in planulae in low salinity conditions indicated that the medusae were transitioning to a benthic polyp life form, which is more resistant to environmental stress. This hypothesis needs further investigation for Eleutheria dichotoma.

Finally, we observed cross-generational changes in the life histories of medusae. First, we found that the salinities experienced by a hydroid colony affected the reproductive rates of medusae. However, medusae experienced these conditions when they were buds attached to a hydranth. Moreover, medusae changed the ratio of reproductive modes with each generation, which may be a sign of damage accumulation or internal rhythms. Further studies are needed to understand this phenomenon.

Acknowledgments We are grateful to Antje Storek-Langbein for her support in organizing matters associated with culturing Eleutheria dichotoma in the laboratory. We also wish to thank Stefan Basler, Merle Bruhn, and Stefan Eckardt for their help in feeding E. dichotoma and Joanna Pijanowska, Oskar Burger, and Hendrik Schubert for their useful comments on the drafts.

Funding Information Open access funding provided by Max Planck Society.

\section{Compliance with Ethical Standards}

The authors declare that they have no conflicts of interests. All institutional and national guidelines for the care and use of laboratory animals were followed. This work was funded by the Max Planck Institute for Demographic Research, Rostock, Germany, for A.D, R.S., and M.J.D. The funders had no role in the study design, data collection or analysis, the decision to publish, or the preparation of the manuscript.

Open Access This article is licensed under a Creative Commons Attribution 4.0 International License, which permits use, sharing, adaptation, distribution and reproduction in any medium or format, as long as you give appropriate credit to the original author(s) and the source, provide a link to the Creative Commons licence, and indicate if changes were made. The images or other third party material in this article are included in the article's Creative Commons licence, unless indicated otherwise in a credit line to the material. If material is not included in the article's Creative Commons licence and your intended use is not permitted by statutory regulation or exceeds the permitted use, you will need to obtain permission directly from the copyright holder. To view a copy of this licence, visit http://creativecommons.org/licenses/by/4.0/.

\section{References}

Amado, E.M., D. Vidolin, C.A. Freire, and M.M. Souza. 2011. Distinct patterns of water and osmolyte control between intertidal (Bunodosoma caissarum) and subtidal (Anemonia sargassensis) sea anemones. Comparative Biochemistry and Physiology Part A: Molecular \& Integrative Physiology 158: 542-551. https://doi.org/ 10.1016/j.cbpa.2010.12.019.

Bavestrello, G., S. Puce, C. Cerrano, E. Zocchi, and N. Boero. 2006. The problem of seasonality of benthic hydroids in temperate waters. Chemistry and Ecology 22: S197-S205. https://doi.org/10.1080/ 02757540600670810 . 
Belkin, I.M., S. Levitus, J. Antonov, and S.A. Malmberg. 1998. "Great salinity anomalies" in the North Atlantic. Progress in Oceanography 41: 168. https://doi.org/10.1016/S0079-6611(98)00015-9.

Bell, G. 1982. The masterpiece of nature: The evolution and genetics of sexuality. Berkeley: University of California Press.

Birrer, S.C., T.B.H. Reusch, and O. Roth. 2012. Salinity change impairs pipefish immune defence. Fish \& Shellfish Immunology 33 (6): 1238-1248. https://doi.org/10.1016/j.fsi.2012.08.028.

Boehm, A.-M., K. Khalturin, F. Anton-Erxleben, G. Hemmrich, U.C. Klostermeier, J.A. Lopez-Quintero, H.-H. Oberg, M. Puchert, P. Rosenstiel, J. Wittlieb, and T.C. Bosch. 2012. FoxO is a critical regulator of stem cell maintenance in immortal Hydra. Proceedings of the National Academy of Sciences 109 (48): 19697-19702. https://doi.org/10.1073/pnas.1209714109.

Boero, F., J. Bouillon, S. Piraino, and V. Schmidt. 2002. Asexual reproduction in the Hydrozoa (Cnidaria). In Progress in asexual reproduction, Reproductive biology of invertebrates, ed. R.N. Hughes K.G. Adiyodi and Rita G. Adiyodi, vol. 11. Chichester: Wiley.

Bøhle, B. 1972. Effects of adaptation to reduced salinity on filtration activity and growth of mussels (Mytilus edulis L.). Journal of Experimental Marine Biology and Ecology 10: 41-47. https://doi. org/10.1016/0022-0981(72)90091-3.

Bouillon, J. 1994. Classe des Hydrozoaires. In Traité de zoologie, volume 3(2), ed. P.-P. Grassé and J. Doumenc, 29-416. Paris: Masson.

Bradley, T.J. 2009. Animal osmoregulation. Oxford: OUP.

Burnham, K.P., and D.R. Anderson. 2003. Model selection and multimodel inference: A practical information-theoretic approach. 2nd edition. Springer Science \& Business Media. ISBN: 0-38795364-7.

Camarda, C.G. 2012. MortalitySmooth: An R package for smoothing Poisson counts with P-splines. Journal of Statistical Software 50: $1-24$.

Canepa, A., J.E. Purcell, M. Bosch-Belmar, M. Acevedo, M. Gentile, and Verónica Fuentes. 2014. Salinity effects on asexual reproduction of Carybdea sp.(Cnidaria: Cubozoa). Journal of Plankton Research 36: 585-590.

Cichoń, M. 1997. Evolution of longevity through optimal resource allocation. Proceedings of the Royal Society B: Biological Sciences 264: 1383-1388. https://doi.org/10.1098/rspb.1997.0192.

Coma, R., M. Ribes, J.-M. Gili, and M. Zabala. 1998. An energetic approach to the study of life-history traits of two modular colonial benthic invertebrates. Marine Ecology Progress Series 162: 89-103.

Dańko, M.J., J. Kozłowski, and R. Schaible. 2015. Unraveling the nonsenescence phenomenon in Hydra. Journal of Theoretical Biology 382: 137-149. https://doi.org/10.1016/j.jtbi.2015.06.043.

Dańko, A., R. Schaible, J. Pijanowska, and M.J. Dańko. 2018. Population density shapes patterns of survival and reproduction in Eleutheria dichotoma (Hydrozoa: Anthoathecata). Marine Biology 165 (3): 110. https://doi.org/10.1007/s00227-018-3309-z.

Donovan, M.R., and M.T. Marr. 2016. dFOXO activates large and small heat shock protein genes in response to oxidative stress to maintain Proteostasis in Drosophila. Journal of Biological Chemistry 291 (36): 19042-19050. https://doi.org/10.1074/jbc.M116.723049.

Downs, C.A., E. Kramarsky-Winter, C.M. Woodley, A. Downs, G. Winters, Y. Loya, and G.K. Ostrander. 2009. Cellular pathology and histopathology of hypo-salinity exposure on the coral Stylophora pistillata. Science of the Total Environment 407 (17): 4838-4851. https://doi.org/10.1016/j.scitotenv.2009.05.015.

Dumont, H.J. 1994. The distribution and ecology of the fresh- and brackish-water medusae of the world. Hydrobiologia 272: 1-12. https://doi.org/10.1007/BF00006508.

Ender, A. 1997. Untersuchungen zur Evolutionsgenetik des athekaten hydrozoans Eleutheria dichotoma (Quatrefages 1842). Dissertation, University of Frankfurt (Main).

Fautin, D.G. 2002. Reproduction of Cnidaria. Canadian Journal of Zoology 80: 1735-1754. https://doi.org/10.1139/z02-133.
Felsenstein, J. 1974. The evolutionary advantage of recombination. Genetics 78 (2): 737-756.

Finkel, T., and N.J. Holbrook. 2000. Oxidants, oxidative stress and the biology of ageing. Nature 408: 239-247. https://doi.org/10.1038/ 35041687.

Folino-Rorem, N.C., and C.J. Renken. 2018. Effects of salinity on the growth and morphology of the invasive, euryhaline hydroid Cordylophora (phylum Cnidaria, class Hydrozoa). Invertebrate Biology 137: 78-90. https://doi.org/10.1111/ivb.12207.

Fraser, C., M. Capa, and P. Schuchert. 2006. European hydromedusa Eleutheria dichotoma (Cnidaria: Hydrozoa: Anthomedusae) found at high densities in New South Wales, Australia: Distribution, biology and habitat. Journal of the Marine Biological Association of the United Kingdom 86: 699-703. https://doi.org/10.1017/ S0025315406013592.

Freire, M., G.N. Genzano, S. Neumann-Leitão, and C.D. Pérez. 2014. The non-indigenous medusa Blackfordia virginica (Hydrozoa, Leptothecata) in tropical Brazil: 50 years of unnoticed presence. Biological Invasions 16 (1): 1-5. https://doi.org/10.1007/s10530-013-0496-x.

Gilchrist, J.D.F. 1919. On a species of the crawling medusa, Eleutheria, from the Cape of Good Hope (Cnidonema capensis, g. et sp. n.) and the southern Eleutheriae. Journal of Cell Science 63: 509-529.

Hadrys, H., B. Schierwater, and W. Mrowka. 1990. The feeding behaviour of a semi-sessile hydromedusa and how it is affected by the mode of reproduction. Animal Behaviour 40: 935-944. https://doi. org/10.1016/S0003-3472(05)80995-9.

Hauenschild, C. 1956. Experimentelle Untersuchungen über die Entstehung asexueller Klone bei der Hydromeduse Eleutheria dichotoma. Zeitschrift für Naturforschung B 11: 394-402.

Hirano, Y.M., Y.J. Hirano, and M. Yamada. 2000. Life in tidepools: Distribution and abundance of two crawling hydromedusae, Staurocladia oahuensis and S. bilateralis, on a rocky intertidal shore in Kominato, Central Japan. Scientia Marina 64: 179-187.

Hoffmann, E.K., and S.F. Pedersen. 2011. Cell volume homeostatic mechanisms: Effectors and signalling pathways. Acta Physiologica 202 (3): 465-485. https://doi.org/10.1111/j.1748-1716.2010.02190.x.

Holst, S., and G. Jarms. 2010. Effects of low salinity on settlement and strobilation of scyphozoa (Cnidaria): Is the lion's mane Cyanea capillata (L.) able to reproduce in the brackish Baltic Sea? Hydrobiologia 645: 53-68.

Hothorn, T., F. Bretz, and P. Westfall. 2008. Simultaneous inference in general parametric models. Biometrical Journal 50 (3): 346-363. https://doi.org/10.1002/bimj.200810425.

Kaplan, E.L., and P. Meier. 1958. Nonparametric estimation from incomplete observations. Journal of the American Statistical Association (JSTOR) 53: 457-481. https://doi.org/10.2307/2281868.

Kawamura, M., and S. Kubota. 2008. Influences of temperature and salinity on asexual budding by hydromedusa Proboscidactyla ornata (Cnidaria: Hydrozoa: Proboscidactylidae). Journal of the Marine Biological Association of the United Kingdom 88: 1601-1606.

Kim, H.-S., C. Skurk, H. Maatz, I. Shiojima, Y. Ivashchenko, S.-W. Yoon, Y.-B. Park, and K. Walsh. 2005. Akt/FOXO3a signaling modulates the endothelial stress response through regulation of heat shock protein 70 expression. The FASEB Journal 19 (8): 1042-1044. https://doi.org/10.1096/fj.04-2841fje.

Kinne, O. 1970. Marine ecology: A comprehensive, integrated treatise on life in oceans and coastal waters. London: Wiley-Interscience.

Klein, J.P., and M.L. Moeschberger. 2010. Survival analysis: Techniques for censored and truncated data. 2. Ed., corr. 3. print. Statistics for biology and health. New York, NY: Springer.

Kleinbaum, D.G., and M. Klein. 2012. Survival analysis: A self-learning text, third edition, Statistics for biology and health. 3rd ed. New York: Springer-Verlag.

Kozłowski, J. 1992. Optimal allocation of resources to growth and reproduction: Implications for age and size at maturity. Trends in Ecology \& Evolution 7: 15-19. 
Leonov, A.V. 2005. Variations in the Black Sea water salinity from its latest salinization to the present state: Estimation based on mathematical modeling. Water Resources 32 (2): 134-144. https://doi.org/ 10.1007/s11268-005-0018-z.

Loewe, L., and A.D. Cutter. 2008. On the potential for extinction by Muller's ratchet in Caenorhabditis elegans. BMC Evolutionary Biology 8: 1.

Ma, X., and J.E. Purcell. 2005. Temperature, salinity, and prey effects on polyp versus medusa bud production by the invasive hydrozoan Moerisia lyonsi. Marine Biology 147: 225-234.

Madsen, K.S., and N.K. Höjerslev. 2009. Long-term temperature and salinity records from the Baltic Sea transition zone. Boreal Environment Research 14(1):125-131.

Martinez, R.L.M.C., and J.D. Naranjo. 2010. A pretest for choosing between logrank and wilcoxon tests in the two-sample problem. Metron 68: 111-125.

Maynard Smith, J., R. Bellig, and G. Stevens. 1978. The evolution of sex. Cambridge Univ Press. ISBN: 978-0-521-29302-0.

Metaxas, A., and R.E. Scheibling. 1993. Community structure and organization of tidepools. Marine Ecology Progress Series (Oldendorf) 98: 187-198.

Mills, C. E., and Y. M. Hirano. 2007. Hydromedusae. In Encyclopedia of Tidepools and Rocky Shores, eds. M.W. Denny, and S.D. Gaines, 286-288. University of California Press. ISBN: 978-0-520-25118-2.

Nadirah, M., W.W.I. Nurhafizah, A.S. Alia, N.A. Iberahim, A.I. Zamani, A.S.A. Soh, A.A. Laith, K.L. Lee, and M. Najiah. 2018. Salinity stress responses in slipper cupped oyster Crassostrea iredalei from Setiu wetlands, Terengganu, Malaysia. Journal of Environmental Biology 39: 754-760. https://doi.org/10.22438/jeb/39/5(SI)/6.

Pechenik, J.A., R. Berard, and L. Kerr. 2000. Effects of reduced salinity on survival, growth, reproductive success, and energetics of the euryhaline polychaete Capitella sp. I. Journal of Experimental Marine Biology and Ecology 254 (1): 19-35. https://doi.org/10. 1016/S0022-0981(00)00261-6.

Poulos, S.E., P.G. Drakopoulos, and M.B. Collins. 1997. Seasonal variability in sea surface oceanographic conditions in the Aegean Sea (eastern Mediterranean): An overview. Journal of Marine Systems 13: 225-244. https://doi.org/10.1016/S0924-7963(96)00113-3.

Purcell, J.E. 2005. Climate effects on formation of jellyfish and ctenophore blooms: A review. Journal of the Marine Biological Association of the United Kingdom 85: 461-476.

Purcell, J.E. 2007. Environmental effects on asexual reproduction rates of the scyphozoan Aurelia labiata. Marine Ecology Progress Series 348: 183-196. https://doi.org/10.3354/meps07056.

Purcell, J.E., U. Båmstedt, and A. Båmstedt. 1999. Prey, feeding rates, and asexual reproduction rates of the introduced oligohaline hydrozoan Moerisia lyonsi. Marine Biology 134: 317-325.

R-Core-Team. 2018. R: A language and environment for statistical computing. Vienna, Austria; 2018.

Reitzel, A.M., A.M. Tarrant, and O. Levy. 2013. Circadian clocks in the Cnidaria: Environmental entrainment, molecular regulation, and organismal outputs. Integrative and Comparative Biology 53: 118 130. https://doi.org/10.1093/icb/ict024.

Remane, A., and C. Schlieper. 1972. Biology of brackish water. Stuttgart, Germany: Schweizerbart Science Publishers.

Rippingale, R.J., and S.J. Kelly. 1995. Reproduction and survival of Phyllorhiza punctata (Cnidaria: Rhizostomeae) in a seasonally fluctuating salinity regime in Western Australia. Marine and Freshwater Research 46: 1145-1151. https://doi.org/10.1071/mf9951145.

Rivera-Ingraham, G.A., and J.-H. Lignot. 2017. Osmoregulation, bioenergetics and oxidative stress in coastal marine invertebrates: Raising the questions for future research. Journal of Experimental Biology 220: 1749-1760. https://doi.org/10.1242/jeb.135624.
Rivera-Ingraham, G.A., A. Nommick, E. Blondeau-Bidet, P. Ladurner, and J.-H. Lignot. 2016. Salinity stress from the perspective of the energy-redox axis: Lessons from a marine intertidal flatworm. Redox Biology 10: 53-64. https://doi.org/10.1016/j.redox.2016.09. 012.

Sampaio, L.A., and A. Bianchini. 2002. Salinity effects on osmoregulation and growth of the euryhaline flounder Paralichthys orbignyanus. Journal of Experimental Marine Biology and Ecology 269: 187-196.

Schierwater, B. 1989. Allometric changes during growth and reproduction in Eleutheria dichotoma (Hydrozoa, Athecata) and the problem of estimating body size in a microscopic animal. Journal of Morphology 200 (3): 255-267.

Schierwater, B., and H. Hadrys. 1998. Environmental factors and metagenesis in the hydroid Eleutheria dichotoma. Invertebrate Reproduction \& Development 34: 139-148.

Schierwater, B., and C. Hauenschild. 1990. The position and consequences of a vegetative mode of reproduction in the life cycle of a hydromedusa and an oligochaete worm. Advances in Invertebrate Reproduction 5: 37-42.

Schlesinger, A., E. Kramarsky-Winter, H. Rosenfeld, R. ArmozaZvoloni, and Y. Loya. 2010. Sexual plasticity and self-fertilization in the sea anemone Aiptasia diaphana. PLoS One 5: s.

Schubert, H., I. Telesh, M. Nikinmaa, and S. Skarlato. 2017. Physiological adaptations. In Biological oceanography of the Baltic Sea, eds. P. Snoeijs-Leijonmalm, H. Schubert, T. Radziejewska, 255-278. Springer Science \& Business Media. ISBN: 978-94-007-0668-2.

Schuchert, P. 2009. The European athecate hydroids and their medusae (Hydrozoa, Cnidaria): Filifera part 5. Revue Suisse de Zoologie 116: 441-507.

Sokolova, I.M., M. Frederich, R. Bagwe, G. Lannig, and A.A. Sukhotin. 2012. Energy homeostasis as an integrative tool for assessing limits of environmental stress tolerance in aquatic invertebrates. Marine Environmental Research 79: 1-15. https://doi.org/10.1016/j. marenvres.2012.04.003.

Soukissian, T., D. Denaxa, F. Karathanasi, A. Prospathopoulos, K Sarantakos, A. Iona, K. Georgantas, and S. Mavrakos. 2017. Marine renewable energy in the Mediterranean Sea: Status and perspectives. Energies 10: 1512. https://doi.org/10.3390/en10101512.

Stearns, S.C. 1992. The evolution of life histories. Vol. 249. Oxford: Oxford University Press.

Tanaka, E.M., and P.W. Reddien. 2011. The cellular basis for animal regeneration. Developmental Cell 21 (1): 172-185.

Therneau, T.M., and P.M. Grambsch. 2000. Modeling survival data: Extending the Cox model. New York, NY: Springer Science \& Business Media.

Venables, W.N., and B.D. Ripley. 2002. Random and mixed effects. In Modern applied statistics with S, 271-300. Springer.

Willcox, S., N.A. Moltschaniwskyj, and C. Crawford. 2007. Asexual reproduction in scyphistomae of Aurelia sp.: Effects of temperature and salinity in an experimental study. Journal of Experimental Marine Biology and Ecology 353: 107-114. https://doi.org/10. 1016/j.jembe.2007.09.006.

Wittlieb, J., K. Khalturin, J.U. Lohmann, F. Anton-Erxleben, and T.C. Bosch. 2006. Transgenic Hydra allow in vivo tracking of individual stem cells during morphogenesis. Proceedings of the National Academy of Sciences 103 (16): 6208-6211. https://doi.org/10. 1073/pnas.0510163103.

Yin, X.W., and W. Zhao. 2008. Studies on life history characteristics of Brachionus plicatilis OF Müller (Rotifera) in relation to temperature, salinity and food algae. Aquatic Ecology 42: 165-176. 